\title{
Towards a better representation of the solar cycle in general circulation models
}

\author{
K. M. Nissen ${ }^{1}$, K. Matthes ${ }^{1}$, U. Langematz ${ }^{1}$, and B. Mayer $^{2}$ \\ ${ }^{1}$ Institut für Meteorologie, Freie Universität Berlin, Carl-Heinrich-Becker-Weg 6-10, 12165 Berlin, Germany \\ ${ }^{2}$ Institut für Physik der Atmosphäre, Deutsches Zentrum für Luft- und Raumfahrt, Oberpfaffenhofen, Germany
}

Received: 17 November 2006 - Published in Atmos. Chem. Phys. Discuss.: 3 January 2007

Revised: 8 August 2007 - Accepted: 10 October 2007 - Published: 17 October 2007

\begin{abstract}
We introduce the improved Freie Universität Berlin (FUB) high-resolution radiation scheme FUBRad and compare it to the 4-band standard ECHAM5 SW radiation scheme of Fouquart and Bonnel (FB). Both schemes are validated against the detailed radiative transfer model libRadtran. FUBRad produces realistic heating rate variations during the solar cycle. The SW heating rate response with the FB scheme is about 20 times smaller than with FUBRad and cannot produce the observed temperature signal. A reduction of the spectral resolution to 6 bands for solar irradiance and ozone absorption cross sections leads to a degradation (reduction) of the solar SW heating rate signal by about $20 \%$.

The simulated temperature response agrees qualitatively well with observations in the summer upper stratosphere and mesosphere where irradiance variations dominate the signal.

Comparison of the total short-wave heating rates under solar minimum conditions shows good agreement between FUBRad, FB and libRadtran up to the middle mesosphere $(60-70 \mathrm{~km})$ indicating that both parameterizations are well suited for climate integrations that do not take solar variability into account.

The FUBRad scheme has been implemented as a subsubmodel of the Modular Earth Submodel System (MESSy).
\end{abstract}

\section{Introduction}

Understanding solar variability effects on climate is an important topic in current studies with state-of-the-art chemistry-climate models (CCMs). If it is possible to understand the influence of solar variability on climate, the contribution of anthropogenic effects to climate change can be better estimated. Variations in the total solar irradiance (TSI) over the 11-year solar cycle are small $(0.08 \%)$ (e.g., Fröhlich,

Correspondence to: K. M. Nissen

(katrin.nissen@met.fu-berlin.de)
2000) and therefore cannot be expected to be the cause for the observed decadal changes in Earth's surface temperature. However, variations in the ultraviolet (UV) part of the solar spectrum, which is important for ozone production and middle atmosphere heating, range from $8 \%$ at $200 \mathrm{~nm}$ to about $5 \%$ from $220 \mathrm{~nm}$ to $260 \mathrm{~nm}, 0.5 \%$ around $300 \mathrm{~nm}$, and $0.1 \%$ above $400 \mathrm{~nm}$ (e.g., Lean et al., 1997; Woods and Rottman, 2002). Much larger variations are observed at shorter wavelengths (over $50 \%$ at $120 \mathrm{~nm}, 10-15 \%$ from $140-200 \mathrm{~nm}$ ), which are mainly absorbed in the higher atmosphere (mesosphere and thermosphere).

As has been shown in past modeling studies (e.g. Brasseur, 1993; Haigh, 1994; Fleming et al., 1995), 11-year solar UV irradiance variations have a direct impact on the radiation and ozone budget of the middle atmosphere. In order to account for these changes a model needs to include spectrally resolved solar irradiance changes as well as ozone changes due to enhanced photo-chemical production (e.g., Larkin et al., 2000). According to a recent study by Shibata and Kodera (2005) the solar forcing of temperature can be regarded as linearly composed of UV and ozone changes. In the annual mean Shibata and Kodera found the UV forcing to be dominant and over twice as large as the ozone forcing around the stratopause and above, while the ozone forcing is dominant below $5 \mathrm{hPa}$ where the UV forcing is negligible. At summer solstice however, the ozone forcing in the polar upper stratosphere reaches the same magnitude as the UV forcing (Langematz and Matthes, 2007 ${ }^{1}$ ). Matthes et al. (2003) showed that general circulation models (GCMs) considering spectral variations between different phases of the 11-year solar cycle show a clear direct solar signal in the temperature and circulation of the upper stratosphere. These studies clearly demonstrate that the wavelengths important for ozone

\footnotetext{
${ }^{1}$ Langematz, U. and Matthes, K.: Sensitivity of the 11-year solar signal to radiation and ozone changes, J. Geophys. Res., in review, 2007.
}

Published by Copernicus Publications on behalf of the European Geosciences Union. 
absorption need to be taken properly into account for solar variability studies.

During solar maximum (hereafter: solar max) years the solar UV irradiance is enhanced, which leads to additional ozone production and heating in the stratosphere and above. By modifying the meridional temperature gradient the heating can alter the propagation properties for planetary and smaller-scale waves that drive the global circulation. Thus the relatively weak, direct radiative forcing of the solar cycle in the upper stratosphere could lead to a larger indirect dynamical response in the lower atmosphere through a modulation of the polar night jet and the Brewer-Dobson circulation (Kodera and Kuroda, 2002). This has recently been confirmed in a GCM study by Matthes et al. (2004) who ascribed the successful simulation of solar variability effects in their GCM partly to the high-resolution short-wave (SW) radiation parameterization and partly to the prescription of realistic equatorial winds throughout the stratosphere. The transfer of the solar signal from the stratosphere to the troposphere is subject of current model and observational studies that suggest different mechanisms: a modulation of the Arctic oscillation (AO) at middle to high latitudes, changes in vertical motion and precipitation in the tropics, and changes in tropospheric mid-latitude baroclinic activity (e.g., Kodera, 2002, 2004; Haigh et al., 2005; Matthes et al., 2006). Such dynamical changes can feedback on the chemical budget of the atmosphere because of the temperature dependence of the chemical reaction rates and transport of chemical species.

In order to simulate the dynamical and chemical feedback mechanisms associated with solar irradiance variations it is essential to calculate the direct, relatively weak additional radiative forcing in the upper stratosphere as accurate as possible. This requires radiation codes with sufficient spectral resolution in the SW bands, as for example pointed out by Matthes et al. (2004) or Egorova et al. (2004). However, for computational efficiency most GCMs use radiation schemes with only a few spectral intervals to calculate SW heating rates.

The aim of this paper is to demonstrate the improvements of the radiative solar signal in the stratosphere that can be achieved when using SW radiation schemes with a sufficient number of spectral intervals. We first introduce in Sect. 2 a radiation parameterization with high spectral resolution, the FUBRad SW radiation scheme for the middle atmosphere (MA). The code considers 49 spectral intervals in the UV and visible (VIS) part of the solar spectrum. This resolution represents in a way an upper limit of spectral resolution for use in a climate model. Note that the term "high-resolution" was chosen with respect to a GCM radiation scheme, and does not refer to the (much higher) spectral resolution of a stand-alone radiation code. FUBRad has been implemented into the ECHAM5/MESSy climate model (Roeckner et al., 2003; Jöckel et al., 2005) as a submodel of the MESSy submodel RAD4ALL, which represents the standard ECHAM5 radiation scheme in a MESSy conform implementation. In
Sect. 3 we validate the FUBRad scheme against the original ECHAM5 SW radiation scheme and a detailed radiative transfer model. In Sect. 4 the impact of 11-year variations in solar UV irradiance on the SW radiation balance is studied for the FUBRad and ECHAM5 schemes while Sect. 5 shows the corresponding temperature responses. In Sect. 6 the results are summarized and discussed, including an estimate of uncertainties in the solar radiative response induced by degrading the spectral resolution in the SW radiation schemes.

\section{The FUBRad scheme}

The FUBRad scheme has been designed for use in a middle atmosphere (MA) GCM. It operates in the stratosphere and mesosphere between 70 and $0.01 \mathrm{hPa}(18$ and $80 \mathrm{~km})$ and takes the relevant radiative processes in this altitude range into account. FUBRad has been updated from the version described in Matthes et al. (2004). It uses 49 spectral intervals in the UV/VIS between 121.56 and $683 \mathrm{~nm}$. Absorption by ozone $\left(\mathrm{O}_{3}\right)$ between 206 and $362 \mathrm{~nm}$ is calculated using spectral irradiances suggested by WMO (1986) and Sander et al. (2003). Temperature-independent absorption cross sections are taken from Molina and Molina (1986) where available (206-347 nm) and from WMO (1986) beween $347-362 \mathrm{~nm}$. Absorption in the Chappuis bands is fitted to the WMO heating rates following Shine and Rickaby (1989). Their factor $F$ has been refitted to $F=322 \mathrm{~W} / \mathrm{m}^{2}$ to avoid overlap with the Near Infrared interval starting at $680 \mathrm{~nm}$.

Heating by molecular oxygen $\left(\mathrm{O}_{2}\right)$ in the SchumannRunge bands and continuum is calculated using the approach of Strobel (1978). The contribution of the Lyman- $\alpha$ line is parameterized using effective cross sections depending on the $\mathrm{O}_{2}$ slant column as suggested by Chabrillat and Kockarts (1997). The energy of absorbed photons is not completely converted to thermal energy, but can also be stored as chemical energy, or be emitted as airglow. Energy losses due to airglow are accounted for by using the efficiency factors of Mlynczak and Solomon (1993) for the Lyman- $\alpha$ line, the Hartley bands and the Schumann-Runge continuum. Table 1 gives the details of the spectral intervals in FUBRad.

As FUBRad operates in the MA (well above the cloud level), backscattering of solar radiation is considered only for $\mathrm{O}_{3}$ in the Chappuis and Huggins bands (Strobel, 1978). FUBRad can be run both as offline model and as interactive submodel of the ECHAM5/MESSy climate model system (Jöckel et al., 2005).

To obtain UV/VIS heating rates for the full vertical domain of the GCM (including the troposphere), FUBRad has been coupled at $70 \mathrm{hPa}$ to the $\mathrm{SW}$ radiation parameterization of Fouquart and Bonnel (1980) (hereafter denoted as FB) which is the standard SW radiation scheme in the ECHAM5 GCM (Roeckner et al., 2003). For a validation of the FB scheme see Wild and Roeckner (2006). The FB scheme 
Table 1. FUBRad wavelength intervals in the shortwave radiation above $70 \mathrm{hPa}$.

\begin{tabular}{lccr}
\hline Band & Gas & Wavelength $(\mathrm{nm})$ & Number of intervals \\
\hline Lyman- $\alpha$ & $\mathrm{O}_{2}$ & 121.6 & 1 \\
Schumann-Runge continuum & $\mathrm{O}_{2}$ & $125.0-175.0$ & 3 \\
Schumann-Runge bands & $\mathrm{O}_{2}$ & $175.0-205.0$ & 1 \\
Herzberg cont./Hartley bands & $\mathrm{O}_{2} / \mathrm{O}_{3}$ & $206.2-243.9$ & 15 \\
Hartley bands & $\mathrm{O}_{3}$ & $243.9-277.8$ & 10 \\
Huggins bands & $\mathrm{O}_{3}$ & $277.8-362.5$ & 18 \\
Chappuis band & $\mathrm{O}_{3}$ & $407.5-682.5$ & 1 \\
\hline & & & total: 49 \\
\hline
\end{tabular}

as implemented in the ECHAM5 GCM resolves only one spectral interval in the UV/VIS part of the spectrum (250$680 \mathrm{~nm}$ ) but takes scattering processes on clouds into account which are important in the troposphere. Technically the coupling is achieved by first calculating absorption in the downward beam down to $70 \mathrm{hPa}$ with FUBRad. The transmissivity on the FUBRad levels is determined and used as input for the FB radiation scheme. The trospospheric albedo can then be calculated (fraction of outgoing to incoming flux at the uppermost FB level) and used as input for the backscattering calculations of FUBRad. The upward optical path is calculated using the diffuse flux approximation factor of Lacis and Hansen (1974).

To obtain solar heating rates for the full solar spectrum (including the near-infrared, NIR) FUBRad uses NIR-heating rates derived from the FB parameterization in 3 spectral intervals between 680 and $4000 \mathrm{~nm}$ at all levels. In the $\mathrm{NIR} \mathrm{O}_{3}$, $\mathrm{H}_{2} \mathrm{O}, \mathrm{CO}_{2}, \mathrm{CH}_{4}, \mathrm{~N}_{2} \mathrm{O}, \mathrm{CO}$ and $\mathrm{O}_{2}$ are taken into account. Aerosols and cloud particles are considered at all intervals.

FUBRad calculates SW heating rates every time step.The code has been optimized for the implementation into the ECHAM5/MESSy model and uses about $7 \%$ of the total computing time of the basic model system.

\section{Validation}

To validate the FUBRad radiation scheme we compare SW heating rates calculated by FUBRad with those from the ECHAM5 4-band SW radiation code of the standard ECHAM5 version (Roeckner et al., 2003) and from a detailed radiative transfer code, libRadtran (Mayer and Kylling, 2005).

Calculations for all models were performed using identical profiles of pressure, temperature, $\mathrm{O}_{3}, \mathrm{O}_{2}, \mathrm{H}_{2} \mathrm{O}, \mathrm{CO}_{2}$ and $\mathrm{N}_{2} \mathrm{O}$ concentrations recommended by the CCMVal project.

\subsection{The ECHAM5 short-wave radiation code}

The ECHAM5 SW radiation code is based on the FB parameterization for the UV/VIS and NIR parts of the solar spectrum. The major difference to FUBRad is the UV/VIS spectral resolution, with 49 intervals in FUBRad compared to only one broad interval in ECHAM5. Note that a recent update of the FB scheme by Cagnazzo et al. (2007) splits the UV/VIS spectrum into 3 bands (instead of 1 band in FB) thereby extending the UV range from $250 \mathrm{~nm}$ to $185 \mathrm{~nm}$. In our study we use for comparison the standard ECHAM5 4band scheme with 1 UV/VIS band. A discussion of the results from the different ECHAM5 SW codes will follow below.

\section{2 libRadtran}

libRadtran is a comprehensive radative transfer package which has been developed and described in detail by Mayer and Kylling (2005). libRadtran is used by a variety of groups which is documented by more than 100 peer-reviewed publications to date (see http://www.libradtran.org/publications. $\mathrm{html}$ ). In a number of intercomparisons, in particular in the UV/VIS spectral range, libRadtran has shown its accuracy - for a list of references please refer to Mayer and Kylling (2005). For the application in this paper libRadtran has been operated in line-by-line mode. $\mathrm{O}_{3}$ and $\mathrm{O}_{2}$ absorption cross sections had to be extended down to $120 \mathrm{~nm}$. This was done following the recommendations by the International Union of Pure and Applied Chemistry (IUPAC) (Atkinson et al., 2004) which lists the most reliable sources for absorption cross section data according to current knowledge.

$\mathrm{O}_{2}$ absorption for the additional spectral regions was compiled from different sources: The Schumann-Runge continuum follows Ogawa and Ogawa (1975) between 108 and $160 \mathrm{~nm}$ and Yoshino et al. (2005) between 160 and $175 \mathrm{~nm}$. In the Lyman- $\alpha$ region, $121.4-121.9 \mathrm{~nm}$, highresolution data from Lewis (1983) is used. Temperaturedependent cross sections in the Schumann-Runge bands (175-205 nm) are taken from Minschwaner et al. (1992). The recommended Herzberg continuum from Yoshino et al. (1988) is added to the Schumann-Runge spectral lines. The same source provides the Herzberg continuum in the wavelength range $205-240 \mathrm{~nm}$. $\mathrm{O}_{3}$ absorption cross sections are temperature-dependent above $185 \mathrm{~nm}$ (Molina and 

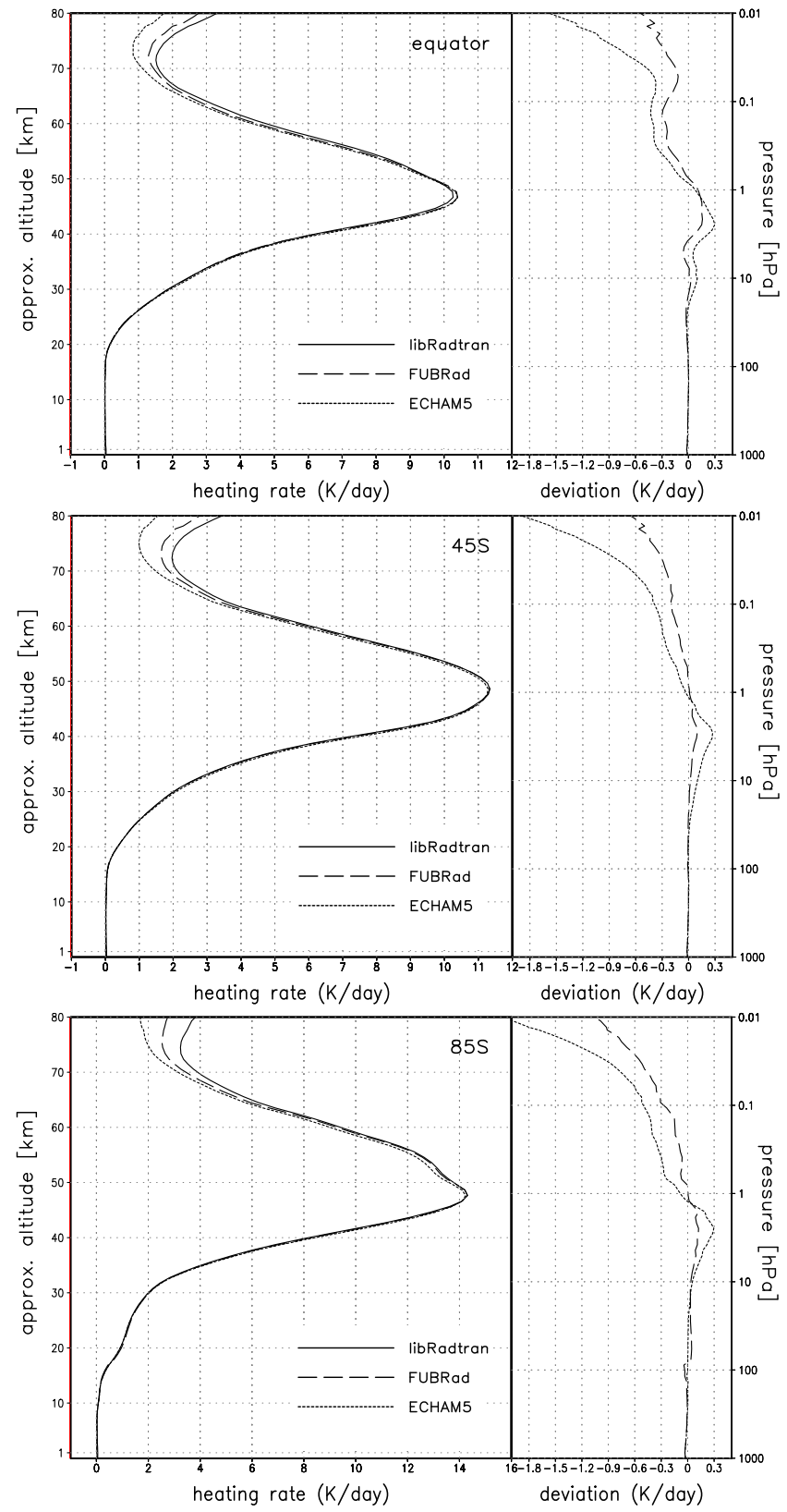

Fig. 1. Daily-mean, short-wave heating rates in K/day for 15 January at the equator, $45^{\circ} \mathrm{S}$ and $85^{\circ} \mathrm{S}$ (left hand side) and deviations to libRadtran (right hand side). Shown for the spectral interval 121$683 \mathrm{~nm}$ for minimum solar irradiance.

Molina, 1986). Below $185 \mathrm{~nm}$, temperature-independent data from Ackerman (1971) is used. To completely resolve all relevant spectral features, more than 10000 wavelengths are included between $121.4 \mathrm{~nm}$ and $683 \mathrm{~nm}$, with a step of $0.001 \mathrm{~nm}$ in the Lyman- $\alpha$ region, $0.003 \mathrm{~nm}$ in the SchumannRunge bands, and otherwise $0.1 \mathrm{~nm}$ below $400 \mathrm{~nm}$ and $1 \mathrm{~nm}$ above $400 \mathrm{~nm}$. The spectral shape of the extraterrestrial irradiance in the Lyman- $\alpha$ region $(121.4-121.9 \mathrm{~nm})$ has been adopted from Chabrillat and Kockarts (1997). Identical extraterrestrial irradiance was used for libRadtran and FUBRad based on the solar variations of Lean (2000). In addition to trace gas absorption, Rayleigh scattering and surface reflection was considered. The Rayleigh scattering cross section by Bodhaine et al. (1999) was used for that purpose. Identical Lambertian surface albedos were used for libRadtran and FUBRad. The radiative transfer was solved with the accurate plane-parallel disort method by Stamnes et al. (1988).

\subsection{Comparison}

SW heating rates were calculated by the three schemes for different solar zenith angles as well as daily mean heating rates using weighted solar zenith angles as recommended by CCMVal. Figure 1 shows examples for the SW heating rates, integrated over the spectral interval $121-683 \mathrm{~nm}$, for $15 \mathrm{Jan}-$ uary at $85^{\circ} \mathrm{S}, 45^{\circ} \mathrm{S}$ and the equator. The NIR is omitted as FUBRad and ECHAM5 use identical parameterizations for this interval and its contribution to the total SW heating rate in the MA is relatively small. The curve denoted FUBRad shows the heating rates obtained by converting the energy of each absorbed photon into thermal energy (i.e. omitting the efficiency factors for airglow). This is consistent with the treatment of absorbed energy in libRadtran and in the FB scheme.

Up to $1 \mathrm{hPa}$ there is close agreement between all codes. Maximum SW heating occurs at the stratopause and reaches nearly $10.5 \mathrm{~K} /$ day at the equator and $14.2 \mathrm{~K} /$ day at $85^{\circ} \mathrm{S}$. Deviations from libRadtran are overall smaller with FUBRad than with ECHAM5, with FUBRad calculating slightly larger heating rates at the stratopause. Below $1 \mathrm{hPa}$ the largest deviation from libRadtran is $0.3 \mathrm{~K} /$ day for ECHAM5 around $40 \mathrm{~km}$, which is less than $4 \%$ of the total heating rate at this level. Good agreement was also found for single solar zenith angles (see also supplementary online material: http://www.atmos-chem-phys.net/7/5391/ 2007/acp-7-5391-2007-supplement.zip).

Above $0.1 \mathrm{hPa}$ libRadtran and FUBRad show considerably larger heating rates than the ECHAM5 code. This is due to the fact, that in contrast to FUBRad and libRadtran, the ECHAM5 scheme does not consider absorption by $\mathrm{O}_{2}$, which dominates in the upper mesosphere.

A comparison of the maximum SW heating rate in January with other radiation codes (from the GRIPS solar cycle study, Matthes et al., 2003, and two more recent CCM studies) reveals that FUBRad lies with $14.7 \mathrm{~K} /$ day inbetween the range from 12.5 to $18.0 \mathrm{~K} /$ day of the other models. Reasons for the heating rate differences may be found in the details of the SW codes used in the models as well as the treatment of ozone in the simulations. The FUBRad SW heating rate was calculated using prescribed WMO ozone fields. It is in excellent agreement with the WMO reference calculations of 14.5 K/day as shown in Shine and Rickaby (1989), and does not reveal any systematic biases. 
In summary, the comparison with the independent lineby-line radiation model shows that both parameterizations (FB and FUBRad) capture the SW heating rates in the stratosphere and lower mesosphere well enough to allow realistic climate simulations up to about $60-70 \mathrm{~km}$ altitude. We thus cannot support the results of Cagnazzo et al. (2007) who found an increase of the SW heating rates in their extended 6-band FB scheme of up to $1.8 \mathrm{~K} /$ day at the summer pole stratopause, when compared to the 4-band FB scheme, resulting in a better agreement with their line-by-line calculations. Our results show an underestimation of the SW heating rate in the ECHAM5 4-band FB scheme at the summer pole stratopause of only $0.2 \mathrm{~K} /$ day when compared to the line-byline model. These discrepancies will be subject of a detailed radiation scheme intercomparison to be performed within the CCMVal activity next year. This will include both line-byline radiation codes as well as GCM radiation codes.

\section{Solar cycle effect on SW heating rates}

To study the influence of variations in UV irradiance during the 11-year solar cycle, we have calculated zonal-mean, daily-mean short-wave heating rates with the offline versions of the FUB (including efficiency factors for airglow) and ECHAM5 radiation codes. Standard input data recommended by the CCMVal project were used including zonalmean temperature, $\mathrm{O}_{3}$ (Fortuin and Langematz, 1994) and $\mathrm{H}_{2} \mathrm{O}$ distributions. $\mathrm{CO}_{2}, \mathrm{CH}_{4}, \mathrm{~N}_{2} \mathrm{O}$ and CFCs are uniformly mixed. Clouds and aerosols are not included. The computation was performed under 15 January conditions. Two calculations were carried out with prescribed variations in UV irradiances at the top of the atmosphere for either solar max or solar min conditions according to Lean (2000). As we are only interested in the effect of the different radiation schemes on the resulting heating rates, we only impose UV changes and no solar-induced $\mathrm{O}_{3}$ variations over the solar cycle. This means that the resulting SW heating rate differences are somewhat smaller than would be the case if SW heating due to solar induced $\mathrm{O}_{3}$ had been considered as well.

Figure 2 shows SW heating rate differences between solar min and solar max calculated with the FUBRad (top) and the ECHAM5 (bottom) schemes. In FUBRad two peaks occur, one centered at the stratopause summer pole reaching $0.21 \mathrm{~K} / \mathrm{day}$, and a second extending over the whole upper summer mesosphere reaching $0.4 \mathrm{~K} /$ day. In contrast, the ECHAM5 scheme produces only one peak at the stratopause. With a maximum SW heating rate difference of $0.01 \mathrm{~K} /$ day the solar signal in ECHAM5 is about 20 times weaker than in FUBRad. In Fig. 3 we compare the SW heating rate differences between solar max and min of FUBRad and ECHAM5 with those derived from libRadtran for an equatorial profile. Over the full vertical domain of the GCM (up to $0.01 \mathrm{hPa}$ ), we find excellent agreement between FUBRad and libRadtran, both assuming total conversion of radiative energy to
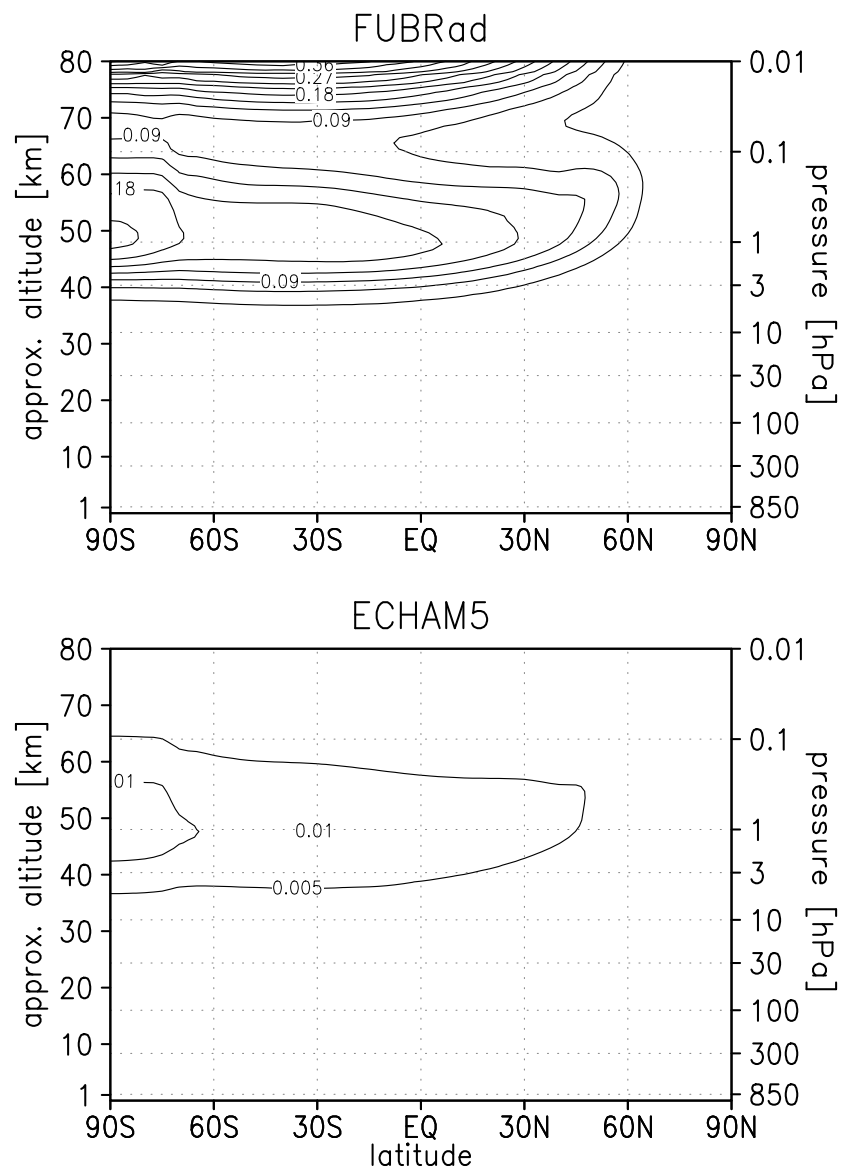

Fig. 2. Daily-mean, zonal-mean short-wave heating rate differences between solar maximum and minimum in K/day for 15 January. Top: FUB radiation scheme, contour interval $0.03 \mathrm{~K} /$ day. Bottom: Fouquart and Bonnel radiation scheme, contour interval $0.005 \mathrm{~K} /$ day.

thermal energy. The heating rate differences reach maxima of $0.15 \mathrm{~K} /$ day at the stratopause and up to $0.4 \mathrm{~K} /$ day at $80 \mathrm{~km}$. Largest differences between solar max and min occur in the upper mesosphere, where FUBRad slightly underestimates solar cycle variability. Inclusion of airglow efficiency factors has a negligible effect on the heating rate differences in the model domain (not shown). In contrast to FUBRad, ECHAM5, with one spectral band in the UV/VIS spectrum, is not able to capture solar cycle variations.

Figure 4 shows the total SW heating rate difference over a solar cycle at the equator as well as the contributions of the different $\mathrm{O}_{3}$ and $\mathrm{O}_{2}$ absorption bands. In the upper mesosphere above about $0.03 \mathrm{hPa}$ the solar signal is dominated by absorption at the Lyman- $\alpha$ wavelength leading to the maximum in SW heating rate differences at the model top of FUBRad (Figs. 3 and 2). As the ECHAM5 scheme does not consider absorption at wavelengths shorter than $250 \mathrm{~nm}$, it does not reproduce the mesospheric maximum. 


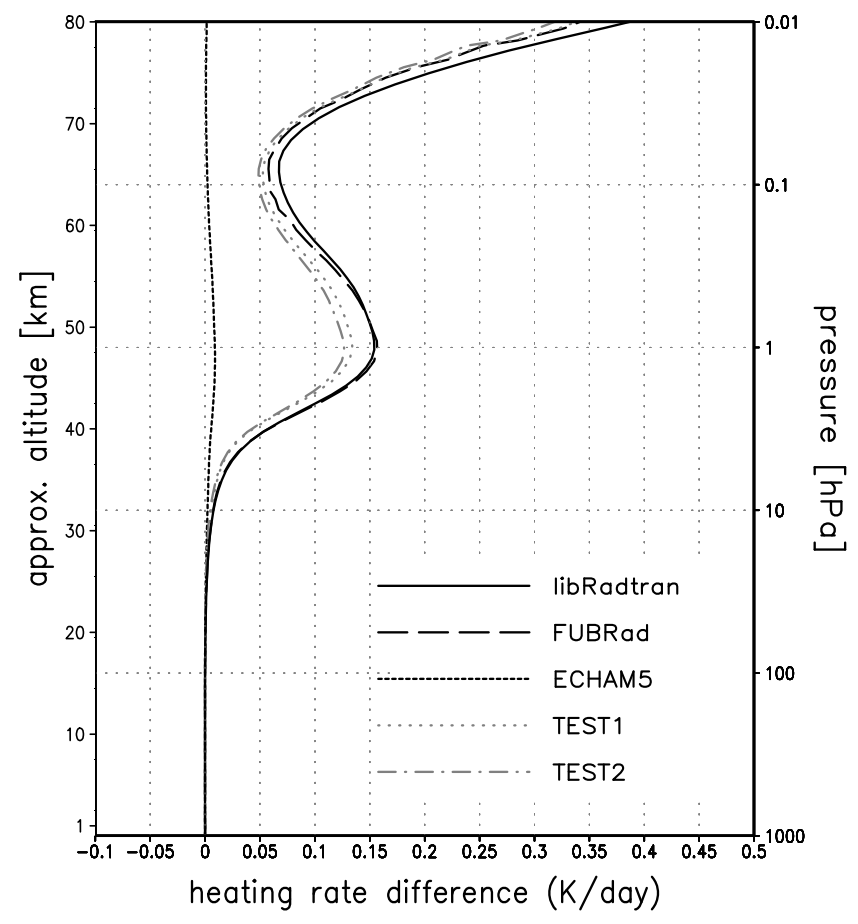

Fig. 3. Difference in daily-mean, short-wave heating rates between solar maximum and solar minimum in K/day. Displayed for 15 January at the equator for the spectral interval $121-683 \mathrm{~nm}$. The profiles displayed in gray (TEST1 and TEST2) show results of sensitivity tests with reduced spectral resolution (see text for details).

Comparison with libRadtran (not shown) suggests that the contribution from the Schumann-Runge bands and continuum is underestimated in FUBRad by a factor of 2 . This explains the deviations in the upper mesosphere in Fig. 3. The maximum of the SW heating rate differences over a solar cycle around the stratopause is due to the combined effect in the Herzberg, Hartley, and Huggins absorption bands. While the Hartley bands dominate the SW heating at the stratopause reaching $0.08 \mathrm{~K} / \mathrm{day}$, the contribution from the Huggins bands is only half that size and is responsible for the SW heating rate difference at lower altitudes in the stratosphere as also shown by Larkin et al. (2000). The contribution of the Chappuis band is negligible.

The spectral resolutions of the FUBRad radiation scheme (49 bands in the UV/VIS) and of the FB scheme (one broad band in the UV/VIS) can be regarded as the upper and lower resolution limits used in GCM SW radiation codes. Other GCM radiation parameterizations use spectral resolutions of a few UV/VIS bands, generally less than 10 bands (see e.g. Matthes et al., 2003). In order to obtain an estimate on how many intervals a radiation scheme should consider to realistically capture solar cycle variations we have performed two tests. The resulting heating rate differences at the equator were added to Fig. 3 (dotted line: Test1; dashed-dotted line: Test2). The first test was designed to assess the im- pact of the spectral resolution of the prescribed solar irradiance. The $49 \mathrm{SW}$ intervals of FUBRad were grouped into 6 broader intervals (Lyman-alpha, Schumann-Runge bands and continuum, Herzberg continuum, Hartley bands, Huggins bands and Chappuis bands). For each group the mean percentage change in the top of atmosphere solar flux between solar max and min was determined using Lean (2000) data. This variation was then uniformly applied to all subintervals within the group. This procedure effectively reduces the number of irradiance intervals from 49 to 6 . The spectral variation of the absorption cross sections was however retained. It was found that the "smearing" of the spectral variation of the UV/VIS irradiance between solar max and min leads to a weakening of the SW heating rate differences at the stratopause by about $16-18 \%$ at different latitudes in the summer hemisphere. In Test2, we used the same broadband grouping as in Test1 (Lyman-alpha, Schumann-Runge bands and continuum, Herzberg continuum, Hartley bands, Huggins bands and Chappuis bands). However in addition to Test1, we applied constant ozone absorption cross sections according to Shine and Rickaby (1989) thus degrading the spectral resolution of the optical parameters. This leads to a further decrease of the solar SW heating rate signal resulting in a 23\% reduction at the stratopause compared to libRadtran and the 49-band FUBRad scheme.

This comparison shows that the accuracy of the calculated radiative response to solar cycle variations depends on the spectral resolution of the SW radiation code. The 49 bands of the FUBRad scheme certainly represent an upper resolution limit applicable in a global climate model. On the other side, 1 to 3 bands are certainly insufficient to simulate the solar signal in SW heating rates. The optimal resolution depends on the accuracy required for individual studies and on the available computer resources.

\section{Temperature response to solar cycle variations}

To determine the temperature response caused by the changes in SW heating rates, we have performed two 25month perpetual January experiments using the FUBRad and ECHAM5 radiation schemes online as submodels of the ECHAM5/MESSy model. We have prescribed the same $\mathrm{O}_{3}$ climatology and concentrations of uniformly mixed species as in the offline experiments and use fixed climatological sea surface temperatures. $\mathrm{H}_{2} \mathrm{O}$ and clouds are determined interactively. The model was run at a horizontal resolution of T42 corresponding to a quadratic Gaussian grid of $2.8^{\circ} \times 2.8^{\circ}$, with 39 vertical levels reaching from the ground up to $0.01 \mathrm{hPa}(80 \mathrm{~km})$. Note that this version of the model does not produce a self-consistent Quasi-Biennial Oscillation (QBO) in the equatorial stratosphere. Solar irradiance at the model top was prescribed using constant solar max and solar min values as described for the offline experiments in Sect. 4 . 


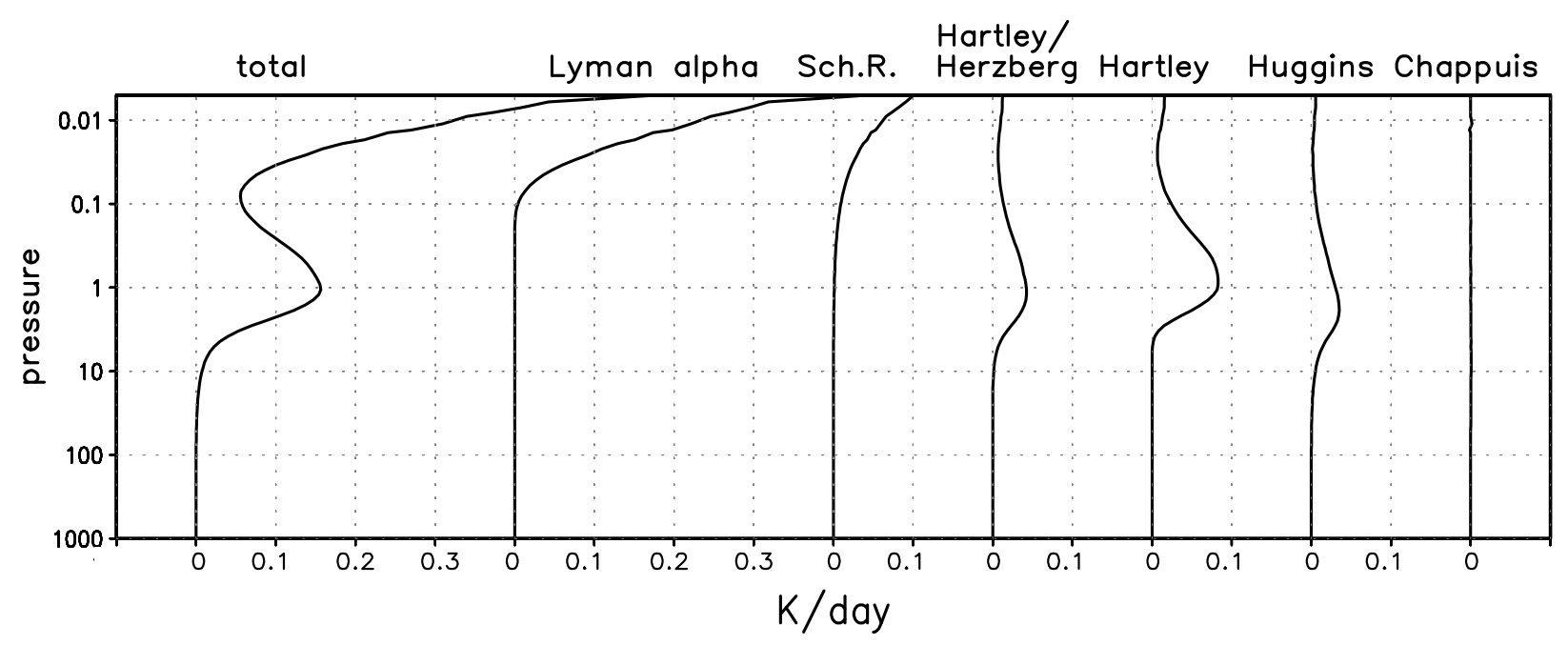

Fig. 4. Differences of short-wave heating rates between solar maximum and solar minimum irradiance in K/day. Daily mean for 15 January at the equator. Total and contribution of the spectral intervals.

The differences in zonal mean temperature between the solar max and min experiments are shown in Fig. 5 for January. Consistent with the SW heating rate differences in Fig. 2 temperatures are higher during solar max throughout the atmosphere except for small regions in the troposphere and two statistically insignificant regions in the NH for the FUBRad scheme (Fig. 5, top). Statistically significant temperature differences reach $0.5-1.0 \mathrm{~K}$ around the tropical stratopause and throughout the upper stratosphere and lower mesosphere in the Southern (= summer) Hemisphere (SH). Compared to the FUB-CMAM solar cycle experiments which used the previous version of the FUBRad scheme (Matthes et al., 2004), there are two improvements: a stronger and significant warming of the upper mesosphere in summer, replacing the unrealistic cooling of the old model, and a significant warming of the tropical mesopause of $1 \mathrm{~K}$. Both signals can be attributed to the extension of the radiation code by UV absorption in the Lyman- $\alpha$ line. A statistically significant secondary temperature maximum of $0.2 \mathrm{~K}$ is located in the tropical lower stratosphere around $20 \mathrm{~km}$.

The simulated temperature differences in Fig. 5 (top) can only qualitatively be compared with observations, as the effect of solar induced ozone variations has been neglected in our sensitivity studies. Thus the modeled temperature signal in the stratosphere should be expected to be smaller than in the observations. Kodera and Kuroda (2002) found in National Centers for Environmental Prediction/Climate Prediction Center (NCEP/CPC) data a warming of the tropical upper stratosphere close to $1 \mathrm{~K}$ in January; Randel (pers. communication) also analyzed a warming of $1.0 \mathrm{~K}$ for annual mean conditions in Stratospheric Sounding Unit (SSU) measurements. The temperature signal in our study (without solar induced ozone effect) reaches $0.5 \mathrm{~K}$ only. However, in a companion study, Langematz and Matthes $(2007)^{1}$ show that the additional warming due to the solar induced ozone increase at solar max is of the order of 0.4 to $0.5 \mathrm{~K}$ in the tropical upper stratosphere. Adding both contributions yields a magnitude of the temperature signal that is in good agreement with observations. It must be noted however that due to the different data sources and analysis methods, uncertainties exist in observational estimates of the solar signal which complicate the validation of the simulated response. E.g., the annual mean solar temperature signal in the upper tropical stratosphere ranges between $1.0 \mathrm{~K}$ and $1.75 \mathrm{~K}$ in different obervational analyses (W. Randel, personal communication; Crooks and Gray, 2005). Interestingly, the model, when using FUBRad, simulates a secondary tropical warming maximum in the lower stratosphere. This maximum is also seen in NCEP/CPC observations (Kodera and Kuroda, 2002) and other model studies (e.g., Matthes et al., 2004). The fact that it occurs in time slice solar cycle experiments, without QBO and with fixed SSTs adds to the discussion which processes are needed in order to reproduce this feature (see e.g. Austin et al., 2007²; Matthes et al., 2007, for further details on this discussion).

Again, consistent with the SW heating rate differences in Fig. 2 no statistically significant warming during solar max that is comparable to the simulations with FUBRad and observations can be detected for the ECHAM5 scheme (Fig. 5, bottom). In contrast to the FUBRad scheme, the simulation with the ECHAM5 scheme shows statistically significant

\footnotetext{
${ }^{2}$ Austin, J., Tourpali, K., Rozanov, E., Akiyoshi, H., Bekki, S., Bodeker, G., Brühl, C., Butchart, N., Chipperfield, M., Deushi, M., Fomichev, V. I., Giorgetta, M. A., Gray, L., Kodera, K., Kinnison, D., Manzini, E., Marsh, D., Matthes, K., Nagashima, T., Shibata, K., Stolarski, R. S., Struthers, H., and Tian, W.: Coupled chemistry climate model simulations of the solar cycle in ozone and temperature, J. Geophys. Res., in review, 2007.
} 

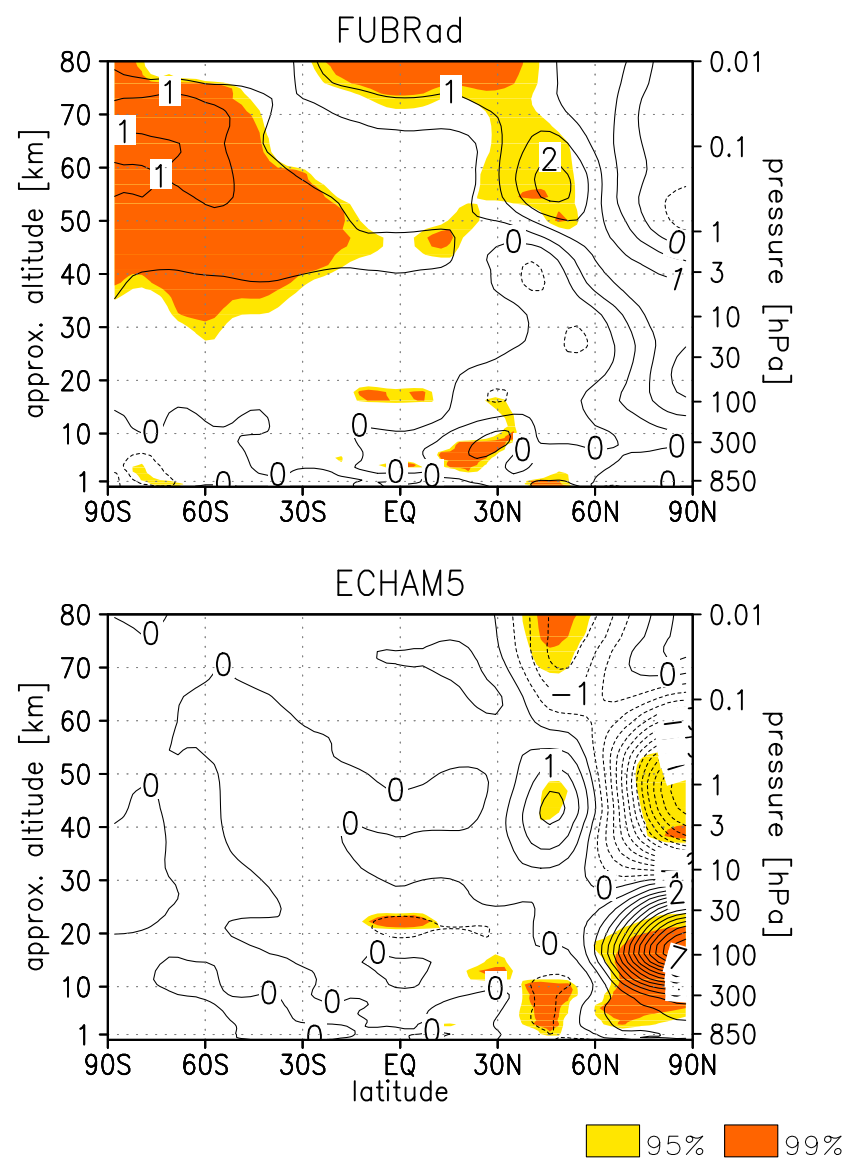

Fig. 5. Longterm-mean temperature difference between solar maximum and solar minimum integration in $\mathrm{K}$. Calculated from perpetual January experiments with the FUBRad (top) and Fouquart and Bonnel (bottom) radiation schemes. Contour interval $0.5 \mathrm{~K}$. Shading: $95 \%$ and $99 \%$ significance levels, calculated with Student's t-test.

anomalies only in the NH. Especially prominent is the dipole at polar latitudes that seems to be an internal model feature but not related to solar cycle influences.

\section{Conclusions}

We have introduced the new SW radiation parameterization FUBRad for use in global climate models. A comparison of the maximum absolute SW heating rate at the summer pole stratopause from different GCM simulations showed that the FUBRad results agree very well with calculations based on WMO reference solar fluxes and absorption cross sections. We have shown that within most of the vertical domain of the ECHAM5 model, both the standard 4-band Fouquart and Bonnel radiation scheme, used in ECHAM5, and the higher resolution FUBRad short-wave scheme give heating rates close to those of a detailed radiative transfer code, libRad- tran, and should produce realistic results in climate integrations.

For solar cycle simulations, however, a radiation scheme with higher spectral resolution is recommended. Our study demonstrates that the SW part of the solar spectrum needs to be adequately resolved in order to perform realistic solar cycle experiments. The variability in irradiance is unequally distributed over the wavelength range with much higher variability at shorter wavelengths. For low-resolution schemes the irradiance changes need to be integrated over a wide spectral range which leads to an underestimation of the variability in SW heating rates. In our example profile we found 20 times stronger variability in heating rates with the highresolution parameterization at the stratopause, in very good agreement with a line-by-line calculation. An estimate of the effect of reduced spectral resolution showed that the radiative response to 11-year solar cycle variations is underestimated by about $20 \%$ in a 6-band UV/VIS radiation scheme with reduced spectral resolution of the solar fluxes as well the ozone absorption cross sections.

In addition to this, it is important to include the absorption by $\mathrm{O}_{2}$ in the Lyman- $\alpha$ band in order to simulate the effect of solar variability on the mesosphere. Solar induced changes in mesospheric temperatures may influence vertical motions associated with the Brewer-Dobson Circulation and thus have non-local effects further down in the atmosphere. We have shown that the updated FUBRad parameterization, introduced in this paper, is suitable for solar cycle studies, as the temperature response to solar cycle variations is in good qualitative agreement with observations.

The FUBRad scheme is available as a submodel to be used by MA GCMs or CCMs and has been implemented into the ECHAM5/MESSy model for solar cycle studies.

Acknowledgements. We would like to thank the reviewers for their efforts and for the valuable comments that clearly improved the paper. We thank M. Giorgetta for providing the offline version of the ECHAM5 radiation code, D. Marsh and D. Kinnison (NCAR, Boulder, USA) for the Lyman- $\alpha$ code, and J. Lean for the spectrally resolved data for the 11-year solar cycle. V. Fomichev and $\mathrm{H}$. Schmidt gave valuable practical advice on different radiation aspects. We particularly thank P. Jöckel for help with the implementation of the FUBRad scheme into the ECHAM5/MESSy model. K. Nissen is supported by the SCOUT-O3 Integrated Project, and K. Matthes by a Marie Curie Outgoing International Fellowship, both within the 6th European Community Framework Programme. Online integrations were performed on the Deutsches Klimarechenzentrum (DKRZ) NEC-SX6 computer.

Edited by: M. Dameris 


\section{References}

Ackerman, M.: UV-solar radiation related to mesospheric processes, in Mesospheric models and related experiments, edited by: Fiocco, G., p. 149-159, D. Reidel Publishing Company, Dordrecht, 1971.

Atkinson, R., Baulch, D. L., Cox, R. A., Crowley, J. N., Hampson, R. F., Hynes, R. G., Jenkin, M. E., Rossi, M. J., and Troe, J.: Evaluated kinetic and photochemical data for atmospheric chemistry: Volume $\mathrm{I}-$ gas phase reactions of $\mathrm{O}_{\mathrm{x}}, \mathrm{HO}_{\mathrm{x}}, \mathrm{NO}_{\mathrm{x}}$ and $\mathrm{O}_{\mathrm{x}}$ species, Atmos. Chem. Phys., 4, 1461-1738, 2004, http://www.atmos-chem-phys.net/4/1461/2004/.

Bodhaine, B. A., Wood, N. B., Dutton, E. G., and Slusser, J.: On Rayleigh oprical depth calculations, J. Atmos. Oceanic Technol., 16, 1854-1861, 1999.

Brasseur, G.: The response of the middle atmosphere to long-term and short-term solar variability: A two-dimensional model, J. Geophys. Res., 98(D12), 23 079-23 090, 1993.

Cagnazzo, C., Manzini, E., Giorgetta, M. A., De F. Forster, P. M., and Morcrette, J. J.: Impact of an improved shortwave radiation scheme in the MAECAHAM5 General Circulation Model, Atmos. Chem. Phys., 7, 2503-2515, 2007,

http://www.atmos-chem-phys.net/7/2503/2007/.

Chabrillat, S. and Kockarts, G.: Simple parameterization of the absorption of the solar Lyman-alpha line, Geophys. Res. Lett., 24, 2659-2662, 1997.

Crooks, S. A. and Gray, L. J.: Characterization of the 11-year solar signal using a multiple regression analysis of the ERA-40 dataset, Climate, J., 18, 996-1015, 2005.

Egorova, T., Rozanov, E., Manzini, E., Haberreiter, M., Schmutz, W., Zubov, V., and Peter, T.: Chemical and ynamical response to the 11-year variability of the solar irradiance simulated with a chemistry-climate model, Geophys. Res. Lett., 31, L06119, doi:10.1029/2003GL019294, 2004.

Fleming, E. L., Chandra, S., Jackmann, C. H., Considine, D. B., and Douglas, A. R.: The middle atmosphere response to short and long term solar UV variations: Analysis of observations and 2D model results, J. Atmos. Terr. Phys., 57, 333-365, 1995.

Fortuin J. P. and Langematz, U.: An update on the global ozone climatology and on concurrent ozone and temperature trends, Proceedings of the International Society for Optical Engineering (SPIE): Atmospheric Sensing and Modelling, 2311, 207-216, 1994.

Fouquart, Y. and Bonnel, B.: Computations of solar heating of the earth's atmosphere: A new parameterization, Beitr. Phys. Atmos., 53, 35-62, 1980.

Fröhlich, C.: Observations of irradiance measurements, Space Sci. Rev., 94, 15-24, 2000.

Gray, L. J., Crooks, S., Pascoe, C., Sparrow, S., and Palmer, M.: Solar and QBO Influences on the Timing of Stratospheric Sudden Warmings, J. Atmos. Sci., 61, 2777-2796, 2004.

Haigh, J. D.: The role of stratospheric ozone in modulating the solar radiative effect on climate, Nature, 370, 544-546, 1994.

Haigh, J. D., Blackburn, M., and Day, R.: The Response of Tropospheric Circulation to Perturbations in Lower-Stratospheric Temperature, J. Climate, 18, 3672-3685, 2005.

Jöckel, P., Sander, R., Kerkweg, A., Tost, H., and Lelieveld, J.: Technical Note: The Modular Earth Submodel System (MESSy) - a new approach towards Earth System Modeling, Atmos. Chem. Phys., 5, 433-444, 2005, http://www.atmos-chem-phys.net/5/433/2005/.

Kodera, K.: Solar cycle modulation of the north Atlantic oscillation: Implication in the spatial structure of the NAO, Geophys. Res. Lett., 29(8), 1218, doi:10.1029/2001GL14557, 2002.

Kodera, K.: Solar influence on the Indian Ocean Monsoon through dynamical processes, Geophys. Res. Lett., 31, L24209, doi:10.1029/2004GL020928, 2004.

Kodera, K. and Kuroda, Y.: Dynamical response to the solar cycle, J. Geophys. Res., 107, 4749, doi:10.1029/2002JD002224, 2002.

Lacis, A. A. and Hansen, J.: A parameterization for the absorption of solar radiation in the earth's atmosphere, J. Atmos. Sci., 31, 118-133, 1974.

Larkin, A., Haigh, J. D., and Djavidnia, S.: The effect of solar UV irradiance variations on the Earth's atmosphere, Space Sci. Rev., 94, 199-214, 2000.

Lean, J.: Evolution of the Sun's spectral irradiance since the Maunder Minimum, Geophys. Res. Lett., 27(16), 2425-2428, doi:10.1029/2000GL000043, 2000.

Lean, J., Rottman, G., Kyle, H., Woods, T., Hickey, J., and Puga, L.: Detection and parameterisation of variations in solar midand near-ultraviolet radiation $(200-400 \mathrm{~nm})$, J. Geophys. Res., 102, 29 939-29956, 1997.

Lewis, B. R., Vardavas, I. M., and Carver, J. H.: The aeronomic dissociation of water vapor by solar H Lyman $\alpha$ radiation, J. Geophys. Res., 88(A6), 4935-4940, 1983.

Matthes, K., Kodera, K., Haigh, J. D., Shindell, D. T., Shibata, K., Langematz, U., Rozanov, E., and Kuroda, Y.: GRIPS solar experiments intercomparison project: Initial results, Pap. Meteorol. Geophys., 54, 71-90, 2003.

Matthes, K., Langematz, U., Gray, L. J., Kodera, K., and Labitzke, K.: Improved 11-year solar signal in the FUB-CMAM, J. Geophys. Res., 109, D06101, doi:10.1029/2003JD004012, 2004.

Matthes, K., Kuroda, Y., Kodera, K., and Langematz, U.: Transfer of the Solar Signal from the Stratosphere to the Troposphere: Northern Winter, J. Geophys. Res., 111, D06108, doi:10.1029/2005JD006283, 2006.

Matthes, K., Kodera, K., Gray, L., Austin, J., Kubin, A., Langematz, U., Marsh, D., McCormack, J., Shibata, K., and Shindell, D.: Report on the first SOLARIS workshop 4-6 October 2006, Boulder, Colorado, USA, SPARC newsletter, 28, 2007.

Mayer, B. and Kylling, A.: Technical Note: The libRadtran software package for radiative transfer calculations: Description and examples of use, Atmos. Chem. Phys., 5, 1855-1877, 2005, http://www.atmos-chem-phys.net/5/1855/2005/.

Minschwaner, K., Anderson, G. P., Hall, L. A., and Yoshino, $\mathrm{K}$.: Polynomial coefficients for calculating $\mathrm{O}_{2}$ Schumann-Runge cross sections at $0.5 \mathrm{~cm}^{-1}$ resolution, J. Geophys. Res., 97, $10103-10108,1992$.

Mlynczak, M. G. and Solomon, S.: A detailed evaluation of the heating efficiency in the middle atmosphere, J. Geophys. Res., 98, 10 517-10 541, 1993.

Molina, L. T. and Molina, M. J.: Absolute absorption cross sections of ozone in the 185- to 350-nm wavelength region, J. Geophys. Res., 91, 14 501-14 508, 1986.

Ogawa, S. and Ogawa, M.: Absorption cross sections of $\mathrm{O}_{2}\left(a^{1} \Delta_{g}\right)$ and $\mathrm{O}_{2}\left(X^{3} \Sigma_{g}^{-}\right)$in the region from 1087 to $1700 \AA$, Can. J. Phys., 53, 1845-1852, 1975.

Roeckner, E., Bäuml, G., Bonaventura, L., Brokopf, R., Esch, M., Giorgetta, M. A., Hagemann, S., Kirchner, I., Kornblueh, L., 
Manzini, E., Rhodin, A., Schulzweida, U., and Tompkins, A.: The atmospheric general circulation model ECHAM 5. PART I: Model description, MPI-Report 349, 127 pp., 2003.

Sander, S. P., Friedl, R. R., Golden, D. M., Kurylo, M. J., Huie, R. E., Orkin, V. L., Morrtgat, G. K., Ravishankara, A. R., Kolb, C. E., Molina, M. J., and Finlayson-Pitts, B. J.: Chemical Kinetics and Photochemical Data for Use in Atmospheric Studies, Evaluation Number 14, Publication 02-25, Jet Propulsion Laboratory, Pasadena, CA, 2003.

Shibata, K. and Kodera, K.: Simulation of radiative and dynamical responses of the middle atmosphere to the 11-year solar cycle, J. Atmos. Sol.-Terr. Phys., 67, 125-143, 2005.

Shine, K. P. and Rickaby, J. A.: Solar radiative heating due to the absorption by ozone, in: Ozone in the atmosphere, edited by: Bojkov, R. D. and Fabian, P., A. Deepak, Hampton, Va., p. 597600, 1989.

Stamnes, K., Tsay, S. C., Wiscombe, W., and Jayaweera, K.: A numerically stable algorithm for discrete-ordinate-method radiative transfer in multiple scattering and emitting layered media, Appl. Optics, 27, 2502-2509, 1988.

Strobel, D. F.: Parameterization of the atmospheric heating rate from 15 to $120 \mathrm{~km}$ due to $\mathrm{O} 2$ and $\mathrm{O} 3$ absorption of solar radiation, J. Geophys. Res., 83, 6225-6230, 1978.
Wild, M. and Roeckner, E.: Radiative fluxes in the ECHAM5 General Circulation Model, J. Climate, 19, 3792-3809, 2006.

Woods, T. and Rottman, G.: Solar ultraviolet variability over time periods of aeronomic interest, in: Comparative Aeronomy in the Solar System, edited by: Mendillo, M., Nagy, A., and Hunter Waite Jr., J., Geophys. Monograph Series, Washington D.C., p. 221-234, 2002.

World Meteorological Organization: Atmospheric ozone 1985, Global Ozone Res. Monit. Proj. Rep. 16/1, Geneva, 1986.

Yoshino, K., Parkinson, W. H., Ito, K., and Matsui, T.: Absolute absorption cross-section measurements of Schumann-Runge continuum of $\mathrm{O}_{2}$ at 90 and $295 \mathrm{~K}$, J. Mol. Spectrosc., 229, 238-243, 2005.

Yoshino, K., Cheung, A. S.-C., Esmond, J. R., Parkinson, W. H., Freeman, D. E.,Guberman, S. L., Jenouvrier, A., Coquart, B., and Merienne, M. F.: Improved absorption cross-sections of oxygen in the wavelength region $205-240 \mathrm{~nm}$ of the Herzberg continuum, Planet. Space Sci., 36, 1469-1475, 1988. 